\title{
Using the Internet to promote sexual health awareness among young people
}

\author{
Makeda Gerressu, Rebecca S French
}

\section{Introduction}

High rates of sexually transmitted infections (STIs) and unplanned pregnancy amongst young people in England emphasise the need to explore innovative ways of delivering sexual health information. The National Teenage Pregnancy Strategy ${ }^{1}$ and the National Strategy for Sexual Health and HIV $^{2}$ advocate better sexual health education. The latter states: "Information on sexual health is often uncoordinated or poorly targeted. It is not consistently accessible and doesn't make enough use of new media and technology". 2

The Internet is a practical, accessible tool for increasing sexual health awareness. ${ }^{3}$ Sexual health sites can be particularly valuable information sources for young people who have trouble accessing sexual health services and can be used to publicise services by providing information that tackles access barriers (e.g. confidentiality for all ages, free emergency contraception, how to get there, and so on).

Access, content, site quality and level of maintenance are four components we feel should be considered prior to the development of sexual health sites. We present these as a starting point to encourage further debate on the use and evaluation of the Internet in sexual health promotion, and to build on Susan Quilliam's review of self-help websites in this issue of the journal (page 329). 4

\section{Access}

The Internet is an increasingly accessible and used information resource in the UK. A recent national study investigating Internet use among young people aged 9-19 years found that $75 \%$ had Internet access at home and over $90 \%$ at school. Over $80 \%$ of users accessed the Internet at least weekly, $25 \%$ of this group used it for personal information and advice and, of these, $22 \%$ reported searching for advice on sex, contraception or pregnancy. 5 In terms of health promotion, the factors influencing home access (e.g. income, cultural resources and gender) may result in the most vulnerable individuals having the least access. However, access and interest do not necessarily equate to the ability to find the desired information and assess the quality of sites.

J Fam Plann Reprod Health Care 2005; 31(4): 267-270

\section{Centre for Sexual Health and HIV Research, Department of Primary Care and Population Sciences, Royal Free and University College Medical School, University College London, London, UK \\ Makeda Gerressu, BSc, MSc, Research Fellow \\ Rebecca S French, RGN, MSc, Senior Research Fellow}

Correspondence to: Makeda Gerressu, Centre for Sexual Health and HIV Research, Department of Primary Care and Population Sciences, Royal Free and University College Medical School, University College London, Mortimer Market Centre, Off Capper Street, London WC1E 6AU, UK. Tel: +44 (0) 207387 9300 ext. 8941. E-mail: mgerressu@gum.ucl.ac.uk
Using the Google ${ }^{\mathrm{TM}}$ search engine, we conducted Internet searches in January 2004 and June 2005 using the following key words: sexually transmitted diseases, pregnancy and contraception, HIV/AIDS, sexuality, sexual health and sex education. Table 1 illustrates the enormous number of resulting hits and the large increase in hits over time. Among the top 10 hits and sponsored links for each keyword there were on average only two sites aimed at or containing a pertinent section for young people. The levels of relevance varied from 'legitimate' sexual health sites to sex-related, commercial (e.g. selling Viagra ${ }^{\circledR}$ or sex toys) and pornographic sites, highlighting the fact that ultimately the responsibility for finding a reliable and age-appropriate site rests with the person undertaking the search.

Reliable statistics on the extent of Internet pornography are not available; however, estimates vary from $1.5 \%$ of all 800 million pages to $85 \%$ of the daily 3900 pages created. 6 Among young people with at least weekly Internet use, $57 \%$ reported having come into contact with online pornography. For one-third of users this was an accidental occurrence while searching for something else. 5

Confidentiality is very important to people seeking sexual health information. The Internet provides anonymity, which can ease the embarrassment associated with seeking sensitive information. However, with schools blocking websites with 'sex' in their content, there are barriers to be overcome. Sexual health sites are particularly vulnerable to indiscriminate restrictions, and it has been recommended that schools should review their Internet filtering systems to avoid blanket-filtering approaches that render educational sites inaccessible. 7

Outside the school setting, attention needs to be paid to how young people can be informed about sites that target them. As part of England's Teenage Pregnancy Strategy, the site RUThinking.co.uk was developed to provide young people with information about sex and relationships. This site was advertised through a large print media and radio campaign that targeted young people. Awareness increased from $17 \%$ among $13-17$-year-olds to $41 \%$ in 4 years. ${ }^{8}$ Awareness was linked to the media campaign, with $50 \%$ of those who had seen or heard at least one advertisement being aware of the website compared to $14 \%$ who had not. This illustrates the need for sustained advertising. New and established sites also need to work with venues and institutions in which young people attend or use the Internet (e.g. youth clubs and schools) to ensure that they are made aware of the available sites and that these are able to be accessed through firewalls.

\section{Content}

Of 16 sexual health sites reviewed, all covered STIs and contraception, albeit with different degrees of detail, but only some discussed other important aspects such as sexuality, body image and the positive aspects of sex. These are comparatively lesser priorities on the public health agenda, but the focus on STIs and contraception may result from the varied objectives of the sites reviewed and the organisations that developed them. Unfortunately, these objectives are not always clearly stated, which can create obstacles for young people when selecting the most appropriate sites and for those promoting the sites to them.

Although none of the participants in Goold et al.'s 
COMMENTARY

Table 1 Word search hits obtained using the Google ${ }^{\mathrm{TM}}$ Internet search engine

\begin{tabular}{|c|c|c|c|c|c|c|}
\hline \multirow[t]{2}{*}{ Search criteria } & \multicolumn{6}{|c|}{ Term(s) searched } \\
\hline & $\begin{array}{l}\text { Sexually } \\
\text { transmitted } \\
\text { diseases }\end{array}$ & $\begin{array}{l}\text { Pregnancy, } \\
\text { contraception }\end{array}$ & HIV/AIDS & Sexuality & Sexual health & Sex education \\
\hline \multicolumn{7}{|l|}{ January 2004} \\
\hline www.google.com & 1120000 & 276000 & 3190000 & 2910000 & 3850000 & 3850000 \\
\hline UK pages & 44000 & 31100 & 291000 & 342000 & 468000 & 468000 \\
\hline \multicolumn{7}{|l|}{ June 2005} \\
\hline www.google.com & 4430000 & 2790000 & 31800000 & 21200000 & 45200000 & 29100000 \\
\hline UK pages & 170000 & 157000 & 774000 & 1090000 & 3060000 & 2160000 \\
\hline
\end{tabular}

study ${ }^{3}$ reported using the Internet to seek sexual health information, when asked, $62 \%$ of the participants said they would use a genitourinary medicine website if one were available and they wanted information on specific conditions, clinic opening times, procedures and locations. Some $70 \%$ of respondents were interested in the option to e-mail a health professional with questions.

Several sites that fulfil the requests of these young people currently exist. They are easy to navigate, provide relevant information and allow peer experiences and concerns to be shared. Some sites also offer e-mail question submissions and message boards where questions and responses are shared. However, the gaps in sexual health information need to be addressed and strong links established between sites.

Engaging the audience is crucial for any message delivery. Maintaining site visitors' interest is very important, particularly when targeting young people, since their attention is sought by many industries, there are vast numbers of information sites, and navigation between sites is easy. A quick glance at sexual health sites reveals a variety of ways to engage young people, including the use of daily updated teenage diaries, interactivity, animated illustrative diagrams, and promises of honest and uncensored information.

Different age groups require different information relevant to their lives and delivery in age-appropriate language. In addition to increasing appeal, this can help minimise the misinterpretation of information. Some sites are better than others at making the target age group very clear from the home page. This can determine whether the visitor ventures beyond the all-important first page. ${ }^{9}$

\section{Quality}

There are no official web certifications. This adds to the burden of finding appropriate sexual health sites without guidance. Although the breadth of information available allows for cross-checking to ascertain information accuracy, outdated and incorrect information - as well as commercial information disguised as educational content are problematic.

Gagliardi and Jadad reviewed 149 website quality rating instruments to evaluate their reliability and validity. ${ }^{10}$ None fulfilled all of their evaluation criteria, which included three main elements: authorship (information on authors, their contributions, affiliations and relevant credentials), attribution (references or sources) and disclosure (site ownership, sponsorship, commercial funding arrangements and potential conflicts of interest). ${ }^{10}$ There are nevertheless several seals found on websites that claim to ensure quality. Who awards them and on what basis is usually not made clear.

Gagliardi and $\operatorname{Jadad}^{10}$ question the necessity or desirability of a quality measure for health information and whether it is achievable when there is no established gold standard. Several organisations have developed criteria to help consumers assess quality health information and there is research being done on whether the presence of validated rating instruments influences consumers' health information. However, it is still unclear whether they impact on the competence, performance, behaviour and health outcomes of those who use them. ${ }^{10}$

\section{Level of maintenance}

The low cost of the Internet is an advantage to both users and information providers. It is a convenient information dissemination tool that can reach a mass audience and is easy to update without high reprinting and distribution costs. However, it is not enough simply to create good websites: like any service providing information, constant updating and checking are vital. As each generation of young people develops new myths about sex and contraception, qualitative research among young people and health care staff is needed to address them.

\section{Conclusions}

The Internet has huge potential to provide a mass audience with access to health information. It is accessible 24 hours a day, is low cost and easy to update. It offers the possibility of maintaining anonymity and can empower people, enabling them to be in control of the information gathering process. This makes it an ideal medium to be promoted for the delivery of sexual health education to help improve sexual health awareness, particularly amongst young people who often have difficulties accessing services.

The sheer volume of information available, the lack of official web certification to ensure the quality and the nature of the topic, makes it particularly difficult to know how to search for reliable and age-appropriate information. However, several high-quality sexual health websites targeting different age groups and managed by reputable sexual health organisations are available. In the UK, Internet access and frequency of use are not the limiting factors since they are both on the rise. The missing link is the promotion of websites as tools to increase sexual health awareness and service access among young people.

Despite a plethora of sexual health information sites aimed at young people, there is little evaluation of the sites, how young people use the Internet to obtain information and the ingredients necessary to make a good sexual health site for this audience. There has also been limited research to date exploring whether the Internet is the most appropriate way of delivering information and, if so, how it can be used in conjunction with other health promotion activities. By presenting four elements to be considered prior to the development and during the maintenance of sexual health websites, this Commentary offers a starting point for the evaluation and promotion of Internet sites as health promotion tools in sexual health. 


\title{
COMMENTARY/VIEW FROM PRIMARY CARE
}

Statements on funding and competing interests

Funding. None identified.

Competing interests. None identified.

References

1 Social Exclusion Unit. Teenage Pregnancy. London, UK: HMSO, 1999.

2 Department of Health. The National Strategy for Sexual Health and $H I V$. London, UK: Department of Health, 2001.

3 Goold PC, Ward M, Carlin EM. Can the Internet be used to improve sexual health awareness in web-wise young people? J Fam Plann Reprod Health Care 2003; 29(1): 28-30.

4 Quilliam, S. Self-help websites. J Fam Plann Reprod Health Care 2005; 31: 329-330.

5 Livingstone S, Bober M. UK Children Go Online: Surveying the Experiences of Young People and Their Parents. London, UK: London School of Economics and Political Science, July 2004. http://www.children-go-online.net
6 Livingstone S. Online Freedom \& Safety for Children. IPPR/Citizens Online Research Publication No. 3, November 2001. http:// www.lse.ac.uk/collections/media@1se/pdf/free safety children1.pdf.

7 Department for Education and Employment (now Department for Education and Skills DfES). Sex and Relationship Education Guidance. Nottingham, UK: DfEE Publications, July 2000. http://www.dfes.gov.uk/sreguidance/sexeducation.pdf.

8 Teenage Pregnancy Strategy Evaluation. Tracking Survey. Report of Results of Twelve Waves of Research October 2004. http://www.dfes.gov.uk/teenagepregnancy/dsp_showDoc.cmf? FileName $=$ TP $\% 20$ WI2\%20report $\% 20$ final\%2E.pdf.

9 Skinner H, Biscope S, Poland B, Goldberg E. How adolescents use technology for health information. J Med Internet Res 2003; 5(4): e32.

10 Gagliardi A, Jadad J. Examination of instruments used to rate quality of health information on the Internet: chronicle of a voyage with an unclear destination. BMJ 2002; 324: 569-573.

\section{"Late deals, package care, it's really Hobson's choice."}

\author{
C T Braicke
}

If the information gleaned from the panellists about a mystery guest on the quiz show What's My Line? was that in his work he sits beside a desk, deals with people and tells them, or rather advises them, where to go, there's a good chance you'd guess he's a travel agent. Wrong! Bill is a general practitioner (GP).

So Bill, tell us about being a GP. Well, it's not so different to being a travel agent, particularly since the Government has introduced 'Choose and Book', an opportunity for patients to choose where they have their hospital treatment. Thank you Bill, that sounds fascinating.

Most GPs have their doubts about 'Choose and Book'; having to spend time with their patients exploring the pros and cons of why they should attend "We've got modern facilities NHS Hospital Trust" rather than "We've always got a nurse for you NHS Hospital Trust". And I'm one of them. My six minutes with the patient isn't enough time to address their concerns as it is, let alone the new concerns allowing them to choose a hospital for their treatment will create. Anyway, when was the last time you selected and booked a holiday in less than six minutes? More importantly, we live by the advice that we should "first do no harm", so let's be honest with our patients and ourselves. I don't know about you, but my knowledge extends to my local hospitals, not those that are outside the area from which I'll accept patients in the first place.

In fact, even this knowledge is being tested. As my local hospitals "develop and progress", I'm finding that more and more I'm having to ring them to find out whether they are still providing care in a particular speciality and, if so, who I should refer my patient to, as consultants now seem to come and go with the same frequency as health ministers. Imagine having to do this for four or five hospitals when you don't even know their phone numbers. It's not like holiday destinations where the star system helps, either. We all know how flawed this system is for

J Fam Plann Reprod Health Care 2005; 31(4): 270

Choisen under Strayne, UK

C T Braicke, General Practitioner hospitals, and that those with the most stars may not be where you'd want your granny treated. After all, what I want next to my bed when I need them is a nurse, not a monitor screen on a robotic arm that, when searching my diagnosis on the Internet, relieves my hospital-acquired constipation.

It's ironic that at a time when the Government's 48-hour access obsession is actually reducing patients' choice (since to achieve this target many practices are no longer letting patients even make an appointment, let alone choose which doctor they want to see), 'Choose and Book' is being forced on us too. With regard to patient choice, it's not the doctor who's playing God, but the Health Minister who giveth with one hand and taketh away with the other.

But NHS hospitals have been imitating the travel industry for a while now. Patients are sent abroad to have their operations, hospitals have hotel wards and, like travel agents who don't send out tickets until a couple of weeks before you're due to travel, many hospitals, in an attempt to achieve their waiting time targets, don't send out appointments until a few days before the appointment either. So I guess it was only a matter of time before general practice became caught up in the travel industry wave.

Realistically speaking, I suppose that I shouldn't be too concerned. Like many vote-winning wheezes, these ideas come and go. Patients vote with their feet anyway. Ask most of them why they've chosen a particular practice and you'll get the answer that it's near and convenient, and not because Dr Braicke has such a great reputation, is up to date with all the recent evidence of best practice, and always makes time for you. Presumably this is also why, before too long, patients will be able to register with two practices, maybe even more than two - for their convenience yes, for their health, probably not. So I'm not going to be trawling through the online hospital brochures and clicking the icon that allows me to compare up to five facilities' specifications at a time. When my patients ask me for my opinion about where they should go for treatment, I'll give them my honest opinion based on what I know, which is how health care should be. And no doubt they'll be delighted, because after all, it's the nearest. 